nologist or the manager to refresh his mind or extend the range of his knowledge. Refresher courses and courses of training for management should be framed with such possibilities in mind. Similarly, the trade unions must increasingly seek to attract into their service some of the ablest minds which the universities and other institutions can put at their disposal.

It is with such issues as these that the Government should be showing concern. There has as yet been little sign that it has a concerted policy, or that it is prepared to take the measures that will be required to win support for an adequate policy of technical education, including education for management as well as preparation of the community for educational change. It is a Government responsibility to see that the educational policy of Britain provides effective safeguards against the ignorance and prejudice which are the most dangerous saboteurs of development and industrial efficiency and prosperity. To dispel misconceptions, to establish confidence and to promote adaptability are the first objectives to which the Government should now be directing its educational and its economic and welfare policies. There is much to be done ; but the Prime Minister's statement on June 5 on economic policy and automation gave little hint that the Government is aware of the needs.

\section{PLASTIC BEHAVIOUR AND DESIGN OF STEEL-FRAME BUILDINGS}

The Steel Skeleton

By Prof. J. F. Baker, M. R. Horne and J. Heyman. Vol. 2: Plastic Behaviour and Design. Pp. $\mathrm{x}+408$. (Cambridge: At the University Press, 1956.) 63s. net.

$\mathrm{D}$ ESPITE the fact that the word 'design' appears in the sub-title of this volume, the steelwork designer might, at first glance, imagine that there is little here for him. This, however, would be an erroneous impression, for it has never been the custom of Prof. J. F. Baker's team to consider an elegant theory as an end in itself. Theory and design are complementary and, in this book, their interrelation has been taken for granted-so much so that important rules of design are in one instance buried in a sub-section. The designer certainly will find adequate guidance in designing steelwork by the plastic method; but he must be willing to relate theory to design, and not expect to find routine procedures handed to him ready-made.

This volume brings the story of Vol. 1 (see Nature, 174,1026 ; 1954) up to the present day. The Bristol and Cambridge researches are fully described; but many structural engineers, alive to recent developments, must already know the story, as it has appeared over the years in various technical journals. It is an instructive tale to those who have yet to read it ; but most will turn with a sense of satisfaction to Chapters 7 and 8, where fundamental theorems and general methods of analysis, respectively, are discussed. Here are the roots of the matter.

The latest developments of plastic design are considered in the chapters on 'shakedown' and on minimum-weight design. 'Shakedown' refers to collapse under live and dead loads which are inde- pendently variable, and the true economy of design is discussed in the second of these chapters. Although it was possible, in the early days, to check plastic theory for shed-type frames by full-scale tests to destruction, it is clearly out of the question to attempt the same procedure with multi-story frames. The behaviour of beams and stanchions in such structures can be predicted only from separate small-scale tests and by logical deduction from the results so obtained.

The 'question marks' or points which are still debatable are, therefore, mostly related to the behaviour of stanchions, and, in the book, a careful survey is made, in three chapters, of all the relevant experimental and theoretical data. The forty-five different types of loading to which a continuous stanchion might be subjected are examined, and nine of the most likely more closely studied. Even this simplification leaves a very wide and complex field in which work remains to be done. Perhaps the other 'question mark' - that of the behaviour of joints-might have had more mention, but know. ledge on this point is scarcely yet at the text-book stage.

Few people during the Second World War knew, as they lay in their Anderson table-shelters, that they were taking part in a test of the principles of ductility and continuity, as applied to structural design. Chapter 17 describes how from the early success of these shelters, which were the first practical structures designed by the plastic theory, grew the two hundred buildings that have proved the effectiveness of the method. It was the frame of a cinema in Bristol which raised the early queries in the minds of Prof. Baker and his colleagues, and it is perhaps fitting that one of the first multi-story frames designed by the new method should be erected in London for the firm of Technicolor, Ltd.

We are still in the early stages of this new development. Progress is likely to be slow if steel designers and fabricators remain too conservative. Visiting American architects admired the slender unity of Hunstanton Secondary School-the first multi-story frame by the plastic method. We should remember that the advance described in this volume is a British development: British architects and structural engineers should be the first to use its advantages. Certainly to the architect the plastic method opens wide opportunities for new structural shapes in steel, and, even if he cannot follow the mathematics, he will find the chapters on load factor and on application and design of real professional value. To the structural engineer this book is of vital importance. He neglects it at his peril unless he is close to retirement. This is the stuff of the future.

W. Fisher Cassie

\section{W. A. LANE: A GUY'S SURGEON}

\section{Sir William Arbuthnot Lane, Bt.}

An Enquiry into the Mind and Influence of a Surgeon. By T. B. Layton. Pp. viii $+128+8$ plates. (Edinburgh and London: E. and S. Livingstone, Ltd., 1956.) $21 s$. net.

'HIS is a remarkable little book which will be of

interest to the large number of surgeons of this generation to whom Lane is known only because his name is attached to certain beautifully designed instruments, and who must therefore wish to know more of the man and his work. The book is dedicated 